\title{
Massive haemorrhagic necrosis of the liver after liver transplantation
}

\author{
S G HÜBSCHER,* D H ADAMS, J A C BUCKELS, P MCMASTER, J NEUBERGER, \\ E ELIAS
}

From the *Department of Pathology, University of Birmingham, and The Liver Unit, Queen Elizabeth Hospital, Birmingham

SUMMARY Six of the first 85 patients who received the first 100 liver transplantations carried out in Birmingham developed a syndrome of fulminant liver failure with distinctive clinical and pathological features. The typical clinical presentation was of an uneventful initial postoperative period, followed by a sudden deterioration in graft function, progressing rapidly to graft failure. All six patients died. The characteristic pathological changes were those of massive haemorrhage and hepatocyte necrosis with only mild inflammation and without occlusive lesions in large arteries or veins. These distinctive features differed from other recognised patterns of graft damage and seemed to comprise a specific post-transplant syndrome.

The pathogenesis was not clear and in the absence of any definite aetiology it is suggested that the term "massive haemorrhagic necrosis" be used to describe these cases. Additional findings seen in five of the six cases were venoocclusive lesions $(n=4)$ and a combination of ductopenia and foam cell arteriopathy $(n=2)$. The presence of these associated lesions suggests that there may be an overlap with other types of graft damage.

After liver transplantation a few patients develop fulminant liver failure of sudden onset and uncertain aetiology. Previously reported cases describe a picture of massive graft necrosis without specific features, and a variety of possible aetiologies including ischaemia, infection, and rejection have been proposed. ${ }^{1-3} \mathrm{We}$ present six such cases with distinctive clinical and pathological features which seem to comprise a specific syndrome.

\section{Material and methods}

The patients' notes, including surgical records, anaesthetic details, and treatment charts were reviewed in detail. Some of the main clinical details are summarised in table 1 . For cases 2,3 , and 4 the initial immunosuppression was intravenous azathioprine $(2 \mathrm{mg} / \mathrm{kg} /$ day $)$ and hydrocortisone $(200 \mathrm{mg} /$ day adult dose, $50 \mathrm{mg} /$ day child dose). Case 1 was given intravenous cyclosporin $5 \mathrm{mg} / \mathrm{kg} /$ day. Cases 5 and 6 received both azathioprine and cyclosporin. When stable, cases $1,2,4$, and 5 were converted to oral cyclosporin $(10 \mathrm{mg} / \mathrm{kg} /$ day $)$ plus oral prednisolone ( $20 \mathrm{mg} /$ day adult dose, $5 \mathrm{mg} /$ day child dose). The

Accepted for publication 3 November 1988 intake of cyclosporin was adjusted to achieve whole blood trough concentrations of $400-750 \mu \mathrm{g} / 1$ as measured by radioimmunoassay with polyclonal antibody (Sandoz). Episodes of acute rejection were treated with high dose steroids $(200 \mathrm{mg}$ oral prednisolone or $1 \mathrm{~g}$ intravenous methyl prednisolone for three consecutive days) in addition to the usual immunosuppressive regimen.

Needle biopsy of the donor liver was carried out immediately following its insertion as a baseline assessment in five patients (cases 1, 2, 4, 5, 6). Eight post-transplant biopsy specimens (seven needle, one wedge), four livers removed surgically at retransplantation, and two necropsy livers were also examined. All post-transplant biopsy material was obtained when there was clinical and biochemical evidence of graft failure and with the informed consent of the patients or their relatives. Necropsy specimens were obtained at 16 hours in case 3 and 20 hours in case 4 .

Tissues were fixed in formalin and embedded in paraffin wax. Sections from each case were stained with haematoxylin and eosin, reticulin, van Gieson, orcein, periodic acid Schiff with and without diastase digestion, and Perls's iron stain. Selected sections were also stained with Elastica-Van Gieson, Martius scarlet blue and the Gram stain. 
Table 1 Clinical summary and timing of biopsies

\begin{tabular}{|c|c|c|c|c|c|c|}
\hline Case No & Age/sex & $\begin{array}{l}\text { Indication for } \\
\text { first transplant }\end{array}$ & $\begin{array}{l}\text { Timing of } \\
\text { biopsies } \\
(\leftarrow\end{array}$ & $\begin{array}{l}\text { Liver failure } \\
\text { time of onset } \\
\text {-Days after first graft }\end{array}$ & $\underset{\rightarrow}{\text { Retransplantation }}$ & Final outcome \\
\hline 1 & $59 / \mathrm{F}$ & Primary biliary cirrhosis & 6 & 10 & 13 & $\begin{array}{l}\text { Died day } 19- \\
\text { disseminated } \\
\text { aspergillosis }\end{array}$ \\
\hline 2 & $40 / M$ & Cryptogenic cirrhosis & 6 & 5 & 8 & $\begin{array}{l}\text { Died day } 10- \\
\text { postoperative } \\
\text { haemorrhage }\end{array}$ \\
\hline 3 & $5 / F$ & Cirrhosis, $\alpha-1-\mathrm{AT}$ & 5 & 4 & & $\begin{array}{l}\text { Died day } 9 \text {-liver } \\
\text { failure }\end{array}$ \\
\hline 4 & $11 / \mathrm{F}$ & Cryptogenic cirrhosis & $6,19,24$ & 20 & & $\begin{array}{l}\text { Died day } 24 \text {-liver } \\
\text { failure }\end{array}$ \\
\hline 5 & $53 / \mathrm{F}$ & Primary biliary cirrhosis & 6,12 & 15 & 16,22 & $\begin{array}{l}\text { Died day } 26- \\
\text { intracerebral } \\
\text { haemorrhage }\end{array}$ \\
\hline 6 & $44 / F$ & Primary biliary cirrhosis & & 3 & 6 & $\begin{array}{l}\text { Died day } 20- \\
\text { disseminated } \\
\text { aspergillosis }\end{array}$ \\
\hline
\end{tabular}

$\alpha-1-\mathrm{AT}=\alpha-1$-antitrypsin deficiency.

Table 2 summarises the histological features assessed and their relative severity in end stage livers obtained at retransplantation or necropsy. The various features assessed were graded semiquantitatively as follows: $1-1=$ absent, $+1-=\min$ imal, $1+=$ mild, $2+=$ moderate, $3+=$ severe. The proportion of hepatocytes which had undergone necrosis was estimated to the nearest $25 \%$. To estimate the number of bile ducts present, 20 small portal tracts were examined at random. The number of these containing bile ducts was counted and expressed as a percentage of the total.

\section{Results}

\section{CLINICAL FEATURES}

The initial operation was uneventful in five of the six cases with a median blood requirement of 9 units (range 4-14 units). Case 3 suffered considerable peroperative blood loss due to bleeding varices and other technical problems and required transfusion with 63 units of blood.

In all six patients there was a sudden deterioration in graft function which progressed rapidly over a period of 24-48 hours to grade IV hepatic coma. In cases 1, 4,

Table 2 Pathological findings in six end stage livers

\begin{tabular}{|c|c|c|c|c|c|c|}
\hline & Case 1 & Case 2 & Case 3 & Case 4 & Case 5 & Case 6 \\
\hline \multicolumn{7}{|l|}{ Parenchyma: } \\
\hline $\begin{array}{l}\text { Extent of necrosis } \\
\text { Inflammation }\end{array}$ & $100 \%$ & $50 \%$ & $100 \%$ & $75 \%$ & $50 \%$ & $75 \%$ \\
\hline \multicolumn{7}{|l|}{ Small portal tracts: } \\
\hline Inflammation & + & + & + & + & ++ & $+1-$ \\
\hline Bile duct number & $100 \%$ & $100 \%$ & $100 \%$ & $10 \%$ & $75 \%$ & $100 \%$ \\
\hline \multicolumn{7}{|l|}{$\begin{array}{l}\text { Bile duct inflammation } \\
\text { Hepatic arteries }(a) \text { : }\end{array}$} \\
\hline Intimal foam cells & - & - & - & + & $t+$ & - \\
\hline Arteritis/fibrinoid necrosis & + & - & - & + & + & - \\
\hline Thrombosis & + & - & - & $\stackrel{+}{-}$ & $\stackrel{+}{-}$ & - \\
\hline \multicolumn{7}{|l|}{ Hepatic veins (b): } \\
\hline Inflammation & + & $+t+$ & - & + & ++ & - \\
\hline Fibrosis & + & + & - & +++ & ++ & - \\
\hline $\begin{array}{l}\text { Thrombosis } \\
\text { Portal veins }(b) \text {. }\end{array}$ & - & + & - & - & - & ++ \\
\hline Endothelial inflammation & - & - & - & + & ++ & - \\
\hline \multirow{3}{*}{$\begin{array}{l}\text { Thrombosis } \\
\text { Gall bladder conduit: } \\
\text { Haemorrhagic necrosis }\end{array}$} & - & - & - & + & - & + \\
\hline & & & & & & \\
\hline & +++ & + & ++ & $++t$ & ++ & + \\
\hline
\end{tabular}

Notes

(a) Changes refer predominantly to segmental and larger arteries

(b) Changes refer predominantly to small and medium-sized vessels. 
362

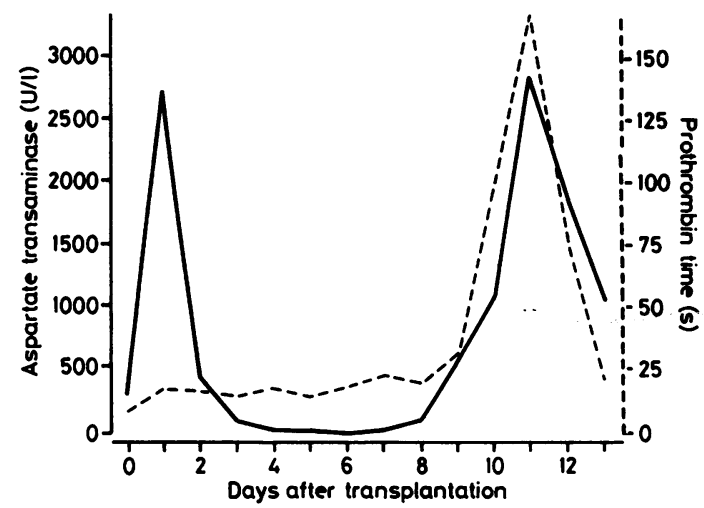

Fig 1 Typical biochemical and clotting profile in massive haemorrhagic necrosis (case 1). The early rise in aspartate transaminase probably reflects a preservation injury. There is then a period of stable graft function for several days followed by a sudden rapid increase in transaminase activity and prothrombin time. These values reach a peak on day 11 and fall again before retransplantation on day 13. The fall in prothrombin time was brought about by the administration of large amounts of fresh frozen plasma.

and 5 liver failure occurred more than seven days after transplantation, following several days with stable graft function. In cases 2,3 , and 6 liver failure occurred earlier (days 5, 4, and 3, respectively). Cases 1, 4, and 5 had early episodes of acute rejection, confirmed his-
Hübscher, Adams, Buckels, McMaster, Neuberger, Elias tologically (see below). These were treated with high dose steroids which resulted in a good clinical response. All six patients died. Cases 3 and 4 died before retransplantation could be carried out. The others were retransplanted, two dying from infection (cases 1 and 6) and two from bleeding (cases 2 and 5).

\section{OTHER LABORA TORY FINDINGS}

Sudden onset of liver failure was characterised biochemically by a rapid increase in serum aspartate transaminase activity (median $7.5 \times$ baseline values, range 3-14 $\times$ ). Bilirubin concentrations remained unchanged or were only slightly increased. A typical biochemical profile is summarised in fig 1 (case 1 ).

Liver failure was also associated with a rapid increase in prothrombin time (median $4 \times$ baseline values, range 2-8×) (fig 1). In case 6 there was a sudden fall in platelets ( 210 on day 3,30 on day 4$)$. The other cases showed no clinically important change in platelet counts, although these were persistently low in three. Other variables of clotting function (fibrin, fibrin degradation products) were not assessed.

Case 3 received an $\mathrm{ABO}$ incompatible graft (donor $A$ negative, recipient $O$ positive). The other patients were matched for blood group but not HLA type. None of the patients had detectable cytotoxic antibodies before surgery. Four had repeat assays at one week which were negative again in two (cases 4

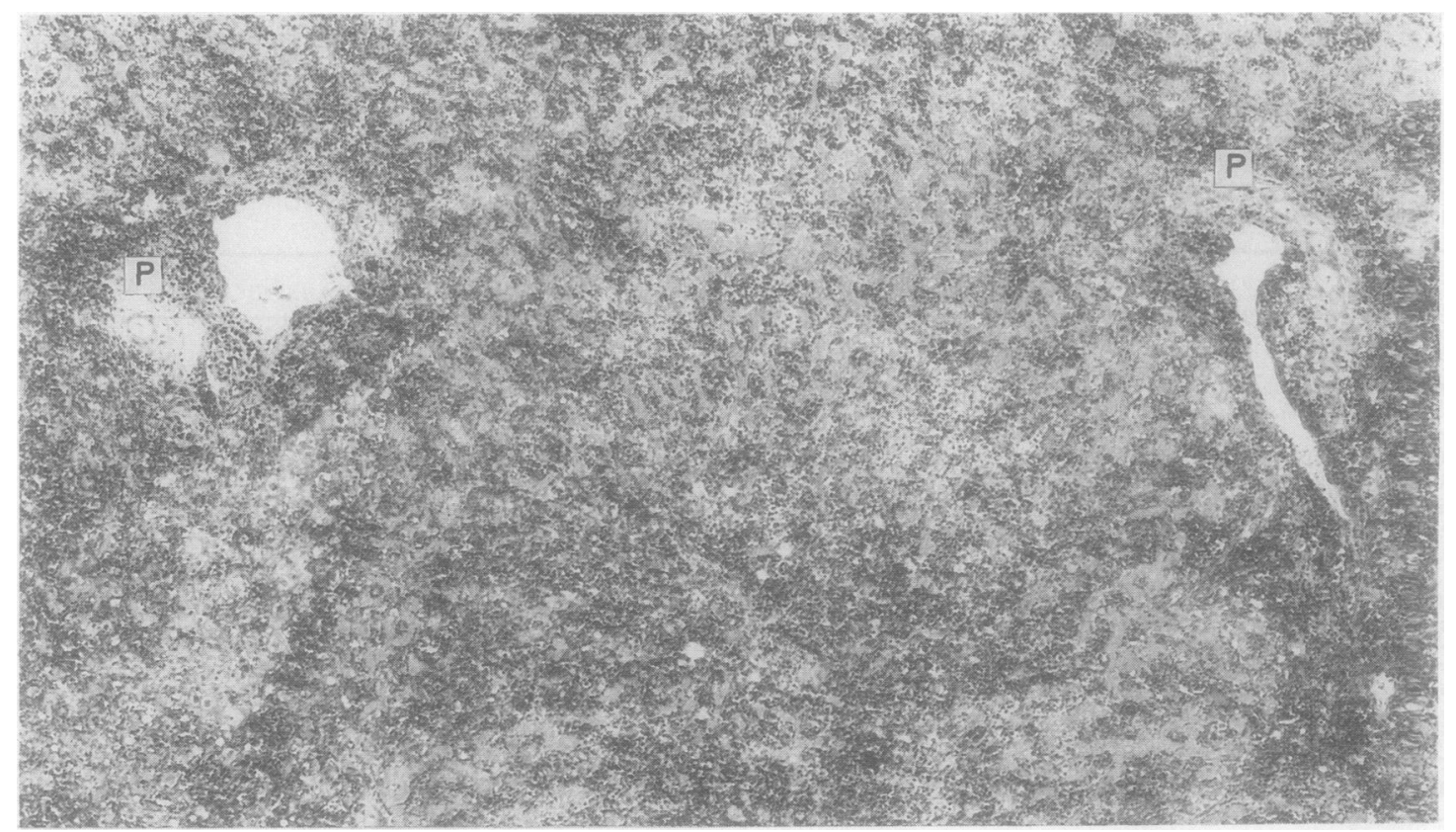

Fig 2 End stage liver in massive haemorrhagic necrosis (case 1, day 13). There is pan-acinar haemorrhage and hepatocyte necrosis. Two surviving portal tracts $(P)$ are present. (Haematoxylin and eosin.) 


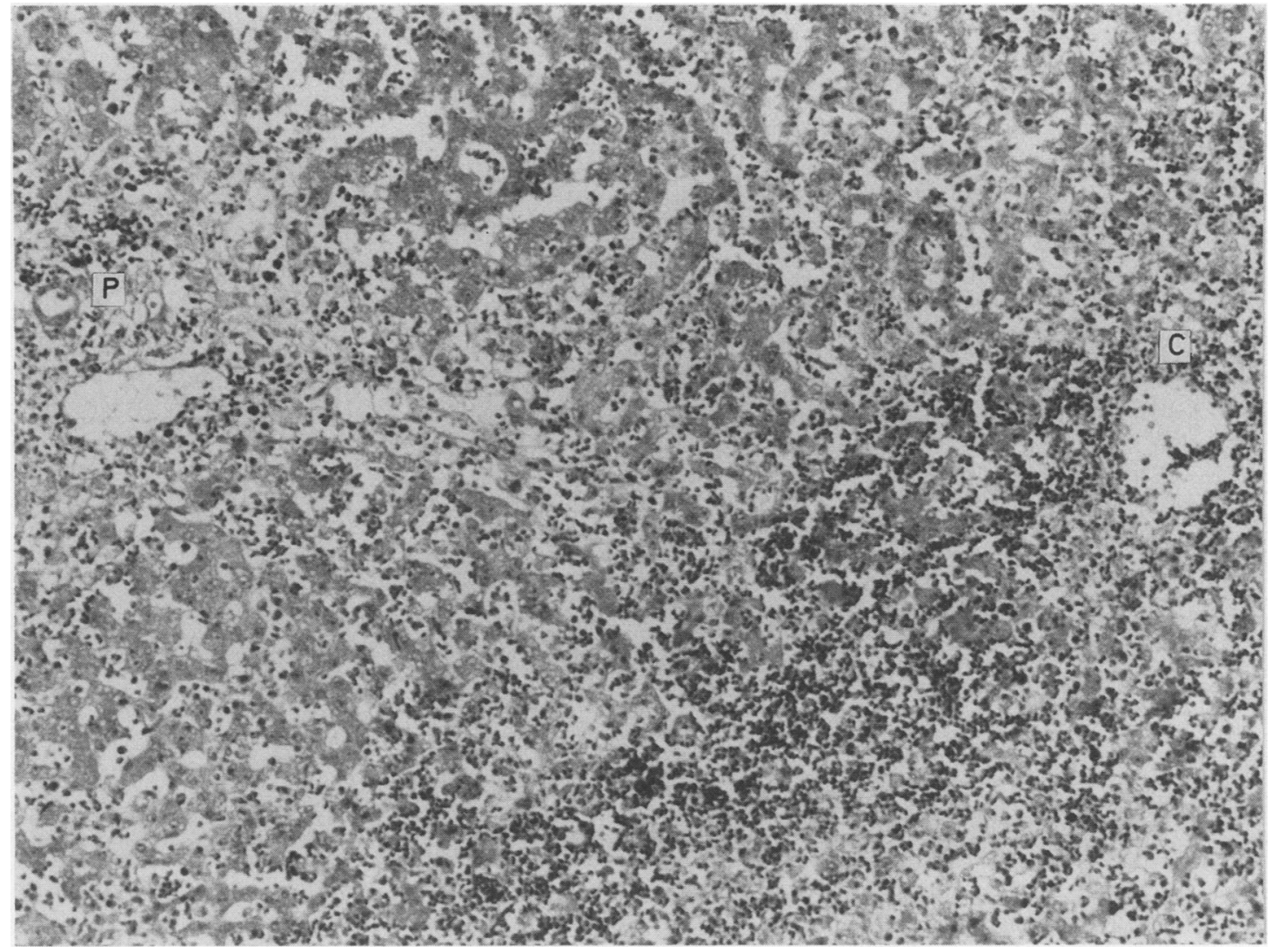

Fig 3 Early lesion of massive haemorrhagic necrosis (case 3, day 5). There is generalised sinusoidal congestion. This is most pronounced in acinar zone 3 where there is early disruption of liver cell plates. Most hepatocytes still appear viable at this stage. ( $P=$ portal tract, $C=$ central vein). (Haematoxylin and eosin.)

and 5) positive at $36 \%$ in case 6 and $78 \%$ in case 2.

Clinically important bacterial infection occurred in only one patient (case 4), who developed an enterobacter urinary tract infection with septicaemia. This occurred 10 days before onset of liver failure and was successfully treated with antibiotics.

All six patients had patent hepatic arteries on angiography.

\section{PATHOLOGICAL FINDINGS}

\section{Peroperative ("time zero") biopsy specimen}

All five biopsy specimens contained sinusoidal aggregates of neutrophil polymorphs consistent with surgical trauma. Four (cases 1, 2, 4, and 5) showed a mild degree of fine cytoplasmic vacuolation in hepatocytes, two (cases 2 and 6) contained occasional small foci of hepatocyte necrosis and two showed mild cholestasis. These changes were most pronounced in perivenular hepatocytes.

Overall, the findings in these specimens did not differ significantly from those obtained peroperatively from other cases during the same period.

Early postoperative biopsy specimens: acute rejection

Three cases $(1,4$, and 5$)$ had early biopsies (all day 6 ) showing features of acute rejection as previously described elsewhere. ${ }^{4}$ Briefly, these comprised: (i) a mixed portal inflammatory infiltrate; (ii) inflammatory cells, especially polymorphs, surrounding and infiltrating bile ducts; (iii) a variable degree of portal and hepatic venular endothelial inflammation. One biopsy specimen (case 4) showed narrow zones of centrilobular haemorrhage and hepatocyte lossthese lesions were not present in the other two biopsy specimens. Case 5 had a further biopsy after treatment (day 12). This showed resolving portal inflammation, again without evidence of centrilobular haemorrhage or necrosis.

Other postoperative biopsy specimens and end stage livers

The remaining four postoperative biopsy specimens 


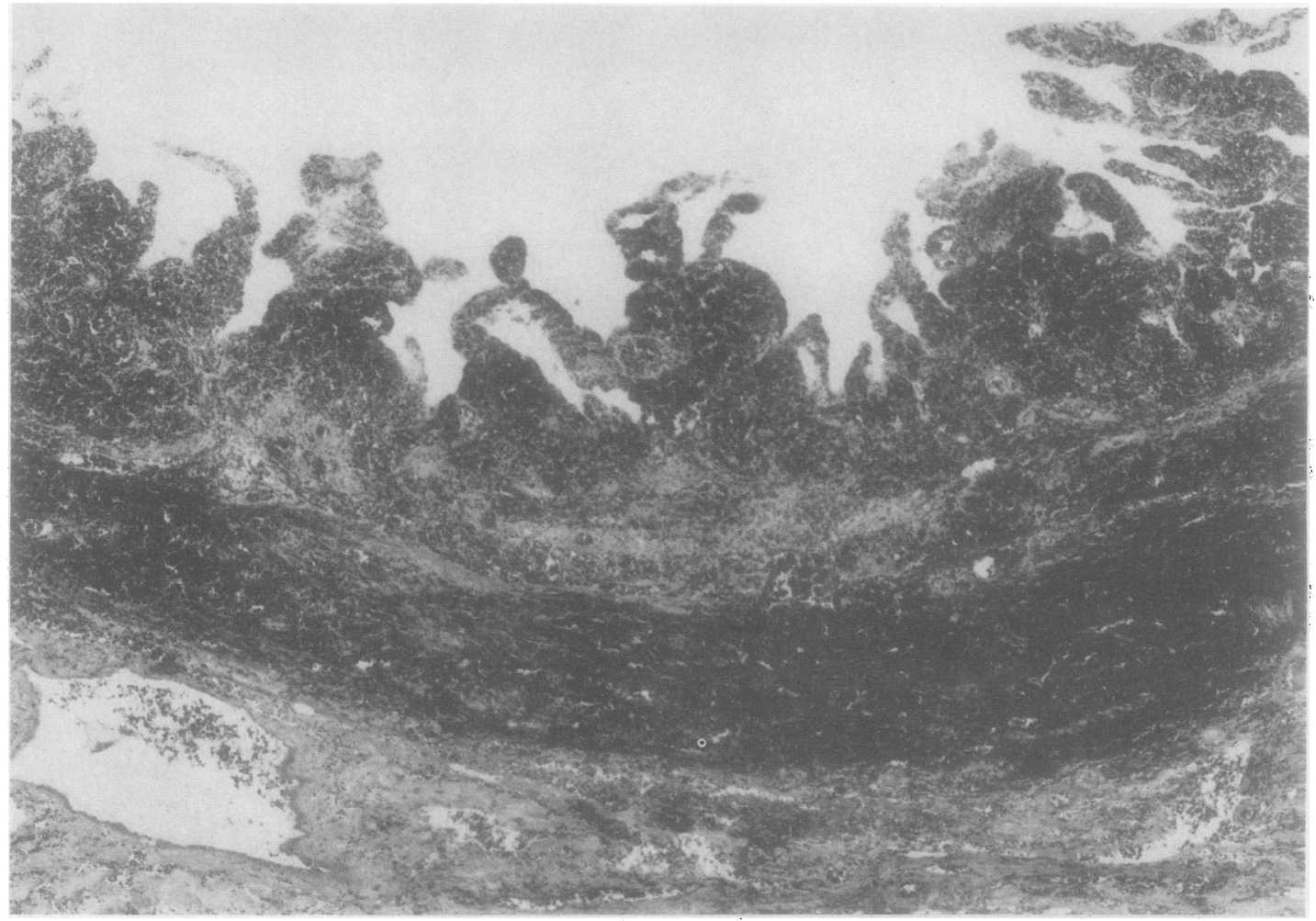

Fig 4 Gall bladder conduit shows transmural haemorrhagic necrosis (case 1, day 13). Similar lesions were present in some of the large bile ducts. (Haematoxylin and eosin.)

and all six whole livers obtained at retransplantation or necropsy showed four main patterns of damage. The histological features seen in the six end stage livers and their relative severity are summarised in table 2.

1 Haemorrhage and hepatocyte necrosis The most striking feature seen in all cases was that of massive haemorrhage and hepatocyte necrosis. Macroscopically this resulted in generalised swelling, congestion, and softening of the graft. The mean weight of the end stage livers was $2000 \mathrm{~g}$ (range 1560-2200 g). Histologically haemorrhage and necrosis were generally most severe in acinar zones 2 and 3 but also had a pan-acinar distribution in many places (fig 2). Hepatocyte necrosis had a mainly coagulative pattern and at least $50 \%$ of hepatocytes were destroyed by this process in the end stage livers. In two cases ( 3 and 4$)$ serial histological material was available for comparison. This showed a haemorrhagic lesion initially confined to perivenular areas with early disruption of liver cell plates (fig 3). At necropsy this lesion had progressed to a pan-acinar distribution with virtually no remaining hepatocytes.
A light mixed inflammatory infiltrate composed of neutrophil polymorphs, lymphocytes, plasma cells and macrophages was usually present in areas of haemorrhagic necrosis. Inflammatory changes were not severe in any of these cases. No viral inclusions were seen histologically and no organisms were shown by Gram staining.

In the earlier and milder lesions portal tracts were generally spared. In the end stage livers there were many areas of haemorrhage into portal tracts associated with necrosis of portal structures. In all cases there was damage to the donor gallbladder conduit: this ranged from a mild focal lesion to transmural haemorrhagic necrosis (fig 4). Inflammatory changes were again relatively minor in these areas.

2 Portal inflammation and bile duct damage Two cases (4 and 5) showed evidence of persistent or recurrent portal inflammation in needle biopsy specimens associated with progressive loss of small bile ducts (fig 5). In the first case bile duct loss was severe with $90 \%$ of small portal tracts being devoid of any recognisable bile ducts by the time of end stage 


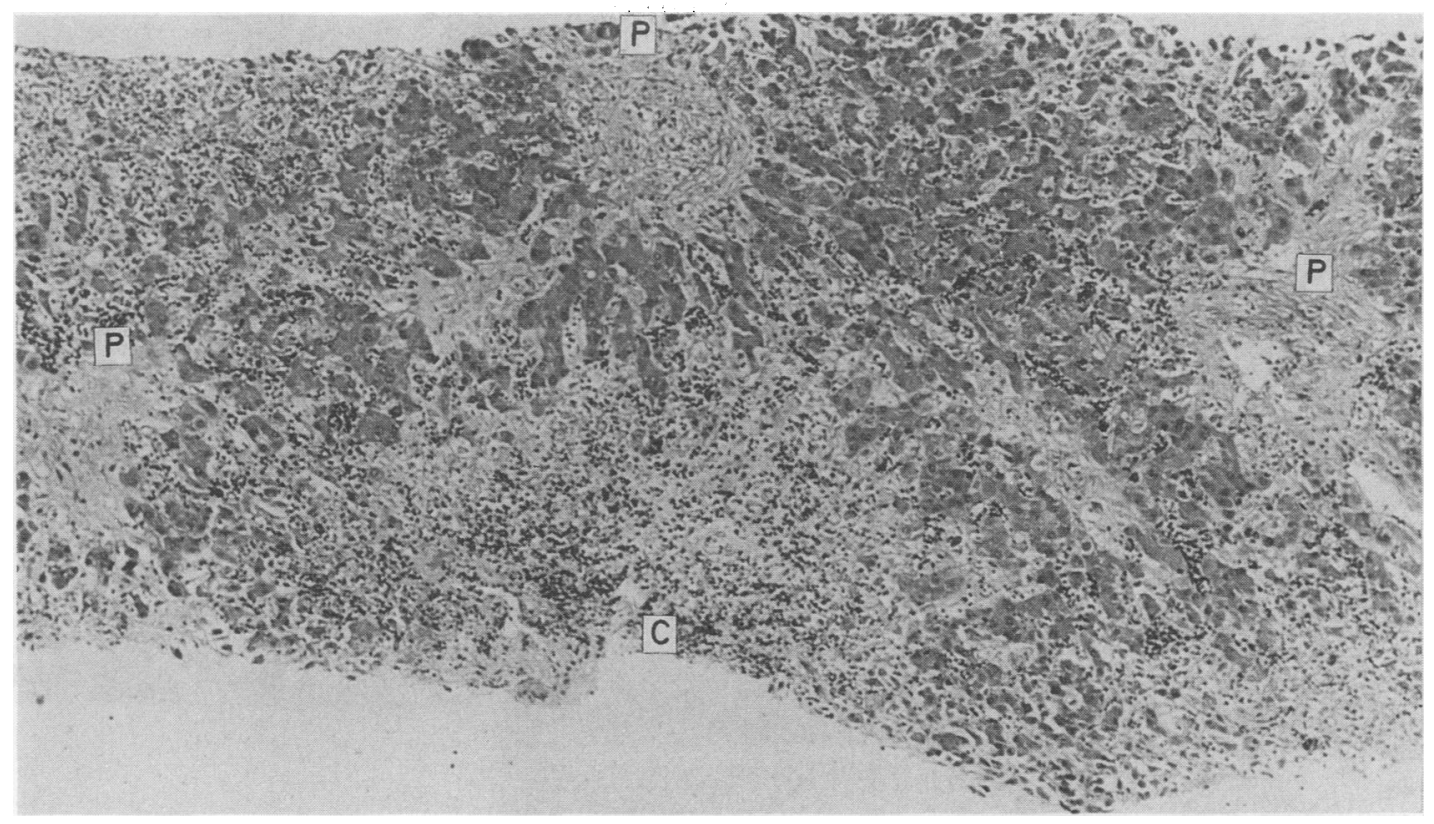

Fig 5 Loss of bile ducts in massive haemorrhagic necrosis (case 4, day 24). There is perivenular hepatocyte necrosis and haemorrhage. Three portal tracts have a "burnt-out" appearance with no gross inflammation and no recognisable bile ducts. Previous biopsy specimens from the same patient had shown a dense portal inflammatory infiltrate with active destruction of bile ducts. ( $P=$ portal tracts, $C=$ central vein). (Haematoxylin and eosin.)

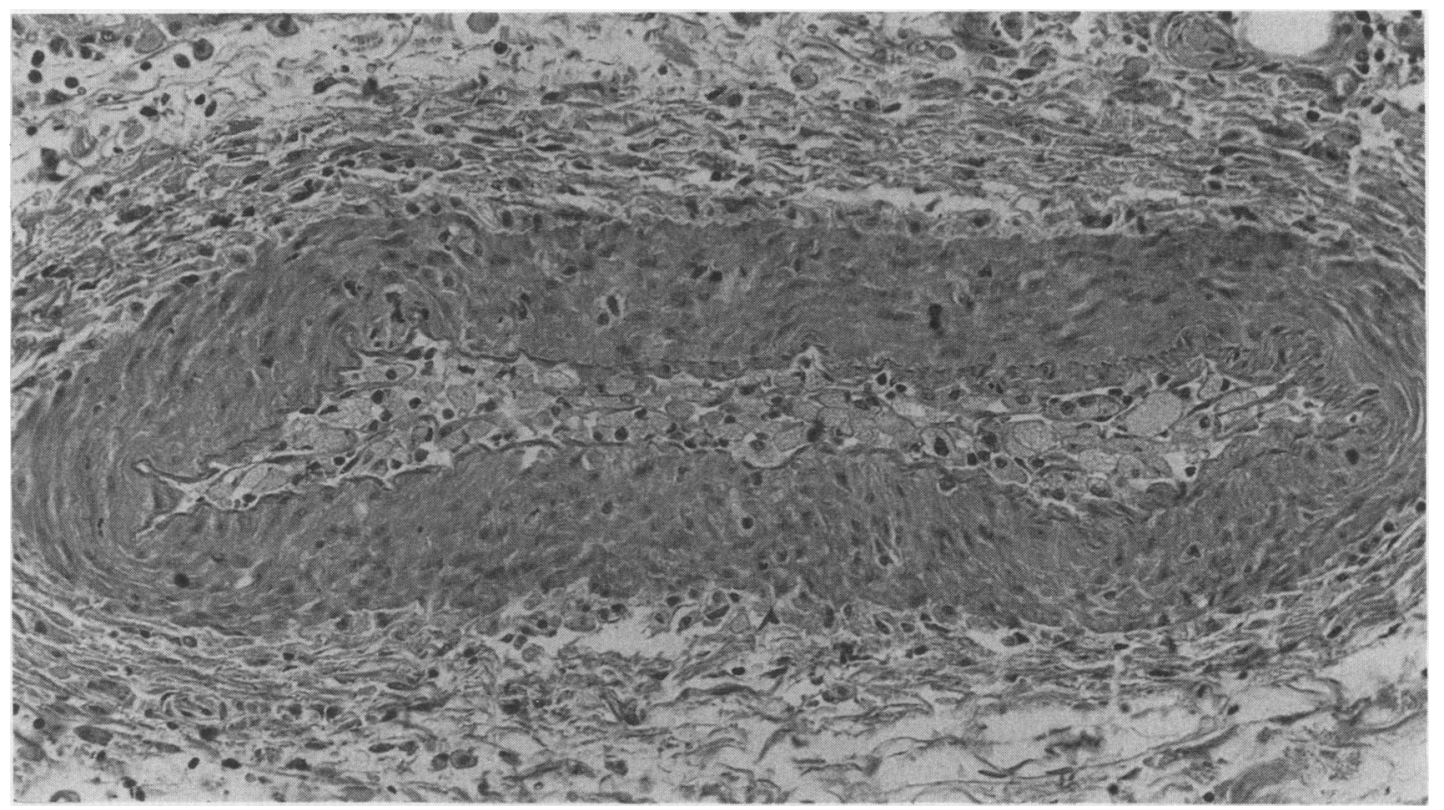

Fig 6 Arterial foam cell lesion (case 5, day 16). A medium sized artery shows luminal occlusion by intimal foam cells. Similar cells are present in the surrounding connective tissue. (Haematoxylin and eosin.) 


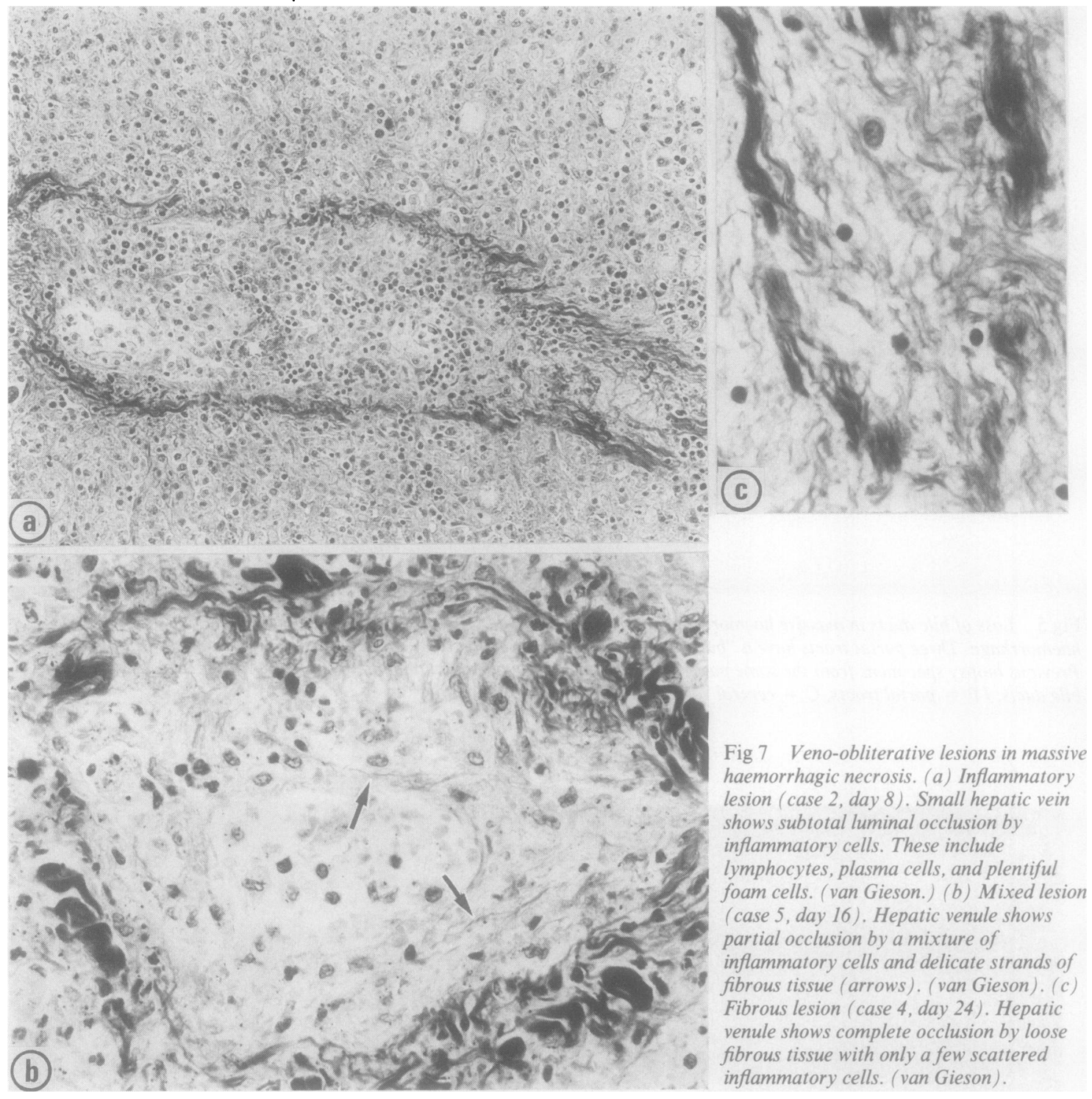

liver disease. The other case was less severe with $25 \%$ loss of ducts. Both cases were associated with arterial foam cell lesions (fig 6).

The other four end stage livers showed only mild, mainly mononuclear, portal inflammation with no evidence of bile duct damage.

3 Arterial lesions The main arterial branches were macroscopically and histologically normal in all six cases. Two cases (4 and 5) showed subendothelial foam cell proliferation in large and medium sized arteries (fig 6). In both cases this lesion was associated

with loss of small bile ducts. Inflammatory changes were seen around and within the wall of some of these vessels-these lesions were rare, mild, and not associated with frank necrotising damage.

Another case (case 1) showed fibrinoid necrosis in the wall of one medium sized artery and occlusive thrombi in two other medium sized vessels.

Smaller arteries and arterioles, unless destroyed by haemorrhagic necrosis, were always normal and showed no evidence of thrombosis or inflammation.

4 Hepatic vein lesions The main hepatic vein bran- 
ches were normal macroscopically and histologically in all six cases.

Four cases (1, 2, 4, and 5) showed hepatic venoobliterative lesions. These were seen in areas of haemorrhagic necrosis, predominantly affecting small hepatic vein branches and were composed of a mixture of loose intimal fibrous tissue and inflammatory cells in varying proportions (fig 7). In cases 2 and 4 these changes resulted in widespread severe luminal narrowing of small hepatic veins. The other two cases were less severely affected.

Cases 2 and 6 showed fibrin thrombi in occasional small and medium sized hepatic veins. In case 2 the presence of these lesions in a needle biopsy specimen taken before retransplantation suggested the possibility of an acute Budd-Chiari syndrome. Examination of the hepatectomy specimen, however, showed that large veins and most medium sized veins were widely patent throughout the graft.

5 Other findings Two cases (4 and 6) showed fibrin thrombi in occasional small portal vein branches. Case 2 showed deposits of fibrin in perivenular sinusoidsthese were not seen in any of the other cases.

\section{COMPARISON OF PATHOLOGICAL FINDINGS IN MASSIVE HAEMORRHAGIC NECROSIS WITH OTHER POST-TRANSPLANT SYNDROMES}

Two hundred and eighty two specimens (246 biopsy specimens, 11 livers removed at retransplantation, and 25 livers obtained at necropsy) were obtained from the remaining 94 transplants of the first 100 carried out. Table 3 summarises the main patterns of damage seen in these specimens.

The histological changes seen in acute rejection, chronic rejection, and graft ischaemia showed some overlap with massive haemorrhagic necrosis. The other types of graft damage (biliary obstruction, "pure" cholestasis, infection and recurrent tumour) were clearly distinct from massive haemorrhagic necrosis and will not be considered any further.

\section{Acute rejection}

In addition to the characteristic portal changes described earlier, several biopsy specimens in this group showed small foci of perivenular hepatocyte loss and congestion. These changes were mild and reversible in cases responding to additional immunosuppression. Four cases showed a loss of bile ducts in association with or following an episode of severe acute cellular rejection. These also returned to normal numbers following additional immunosuppression. ${ }^{5}$ Most of the biopsy specimens in this group were obtained in the early period (day 5-15) after surgery.
Table 3 Patterns of graft damage (other than massive haemorrhagic necrosis) seen in 100 liver transplants

\begin{tabular}{ll}
\hline Pattern of damage & No of cases \\
\hline Acute rejection & 55 \\
Chronic rejection & 13 \\
Ischaemia/infarction & 17 \\
Biliary obstruction & 5 \\
"Pure" cholestasis & 14 \\
Infection (Aspergillus 7*) & 12 \\
$\quad$ (Candida 5*) & \\
Recurrent tumours & 4 \\
\hline
\end{tabular}

*Three cases had aspergillosis and candidiasis.

\section{Chronic rejection}

This was defined as an irreversible condition with loss of bile ducts resulting in graft failure. ${ }^{6}$ In post-transplant biopsy specimens characteristic changes were seen in portal tracts in the form of inflammation (mainly mononuclear) with bile duct damage and a progressive loss of ducts. Centrilobular areas also showed hepatocyte loss and cholestasis. Hepatocyte loss had a lytic pattern and was often accompanied by mild congestion in the early stages. With time, zones of hepatocyte loss were replaced with fibrous tissue and congestion became less severe. All end stage livers obtained at necropsy or retransplantation showed a characteristic foam cell or fibrous lesion in the intima of large and medium sized arteries. ${ }^{?}$

Most of the specimens in this group were obtained at a later date than cases of massive haemorrhagic necrosis. The median graft survival with chronic rejection was five months. Three cases, however, showed a significant loss of bile ducts within four weeks of transplantation - an "acute vanishing bile duct syndrome".

\section{Ischaemia/infarction}

These cases were characterised by areas of coagulative hepatocyte necrosis ${ }^{9}$ accompanied by varying degrees of inflammatory infiltration. Focal congestion was commonly present but a diffuse haemorrhagic lesion was not seen in any of these cases. An underlying cause for ischaemia was identified in 14 of 17 cases: Eight had technical problems with transplantation, complicated by bleeding and hypotension; three had hepatic artery thrombosis; one had inferior vena caval thrombosis causing an acute Budd-Chiari syndrome; one had a donor liver with very small vessels which were thought inadequate for proper perfusion and one had persistent postoperative hypotension probably related to cardiac dysfunction caused by opportunistic fungal infection. In three cases no adequate cause for ischaemia was found. One of these had multiple subcapsular infarcts at necropsy. Another had a needle biopsy specimen showing recent infarction with 
a neutrophil infiltrate-subsequent biopsy specimens showed no evidence of ischaemia and this patient was alive and well with stable graft function at the time of writing. The remaining case had a biopsy specimen showing haemorrhagic infarction. This patient had severe cerebral complications and died as a result. Necropsy was not carried out. Fifteen cases in this group died with a median survival of 16 days.

\section{Discussion}

The six cases described here all have a similar mode of clinical presentation and characteristic pathological changes in which the main feature is that of massive haemorrhagic graft necrosis. These features are sufficiently distinctive and different from other recognised patterns of graft damage to suggest that they constitute a specific post-transplant syndrome.

Previous accounts of liver allograft pathology describe occasional cases of fulminant liver failure of uncertain aetiology occurring in the early postoperative period. ${ }^{1-310}$ Pathological details are generally lacking in previous reports, making direct comparison with our cases difficult. Nevertheless, all of these most probably represent the same or a closely related phenomenon. The mechanisms underlying this process of acute graft failure are poorly understood. Several possible aetiologies have been suggested but, as yet, none has been conclusively confirmed.

An ischaemic aetiology, possibly related to hepatic arterial kinking, was first suggested by Starzl et al ${ }^{11}$ but there has been no further radiological evidence to support this hypothesis. An ischaemic component cannot be ruled out, particularly in view of the predominantly coagulative pattern of necrosis present, but the overall pattern of damage seen in our cases of massive haemorrhagic necrosis differs from that seen in ischaemic damage due to hypotension or hepatic artery thrombosis. Haemorrhage is not present to the same extent in the latter cases.

The presence of large numbers of Gram negative bacilli both in necrotic liver and peripheral blood in some of these cases ${ }^{210}$ raises the possibility of an infective aetiology. Studies in dogs, however, suggest that bacterial colonisation is probably a secondary event in an already damaged liver rather than the primary cause of graft necrosis. ${ }^{12}$ None of our cases had any evidence of infection in blood or bile cultures and Gram staining in liver sections was uniformly negative.

Several viruses occasionally cause fulminant hepatitis in immunocompromised patients. Herpes simplex, zoster, and adenovirus have all been described as causes of massive hepatic necrosis. ${ }^{13-17}$ Liver failure in these cases usually occurs as part of a spectrum of lesions caused by disseminated viral infection. None of our cases had any features suggestive of viral infection, either clinically, or in the liver and other organs at necropsy. Massive haemorrhagic necrosis with a relatively minor cellular component is also described in some cases of neonatal and infantile enterovirus infection. ${ }^{1819}$

The possibility of uncontrolled rejection as a cause for fulminant liver failure was first suggested by Starzl et al, who described three cases of so-called "rejection crisis". ${ }^{20}$ Although three of our cases had early episodes of acute rejection, all responded initially to high dose steroids and none of the later biopsy specimens or end stage livers showed the typical features of acute cellular rejection. ${ }^{3421} 22$ In particular, the paucity of cellular infiltration within necrotic areas offers evidence against a cell mediated immunological reaction.

Massive haemorrhagic necrosis with only minimal cellular infiltration has recently been described in an animal model of hyperacute humoral-mediated rejection. ${ }^{23}$ Hyperacute rejection is not well documented in human liver allografts although one case was reported by Snover. ${ }^{24}$ Although hyperacute rejection is an attractive hypothesis for our cases of massive graft necrosis, the mode of presentation is not in keeping with hyperactue rejection as described in other organs; all of our cases had a clear interval of stable graft function of at least three days before onset of sudden graft failure. The importance of ABO incompatibility in case 3 is uncertain. Although this patient sustained an earlier deterioration clinically, the histological features were indistinguishable from the other five who were $A B O$ identical or compatible. An improved survival in patients receiving ABO identical grafts, when compared with non-identical grafts, has recently been reported in a large series of 520 patients. ${ }^{25}$ The reasons for this are unclear and there is no evidence that poor survival in the latter group is related to problems with rejection. No examples of hyperacute rejection were reported in any of these cases.

The possibility of a "single organ" Schwartzmann reaction as a cause for massive graft necrosis has been suggested by Portmann et al,$^{10}$ who describe one case with a histological picture of haemorrhagic infarction associated with the presence of large numbers of Gram negative bacilli and sinusoidal deposits of fibrin. A similar lesion has been produced experimentally in the liver of rabbits by a Schwartzmann mechanism using $E$ coli $^{26}$ and viral reagents, adenovirus, and hepatitis B surface antigen. ${ }^{27}$

Although the main pathological feature that characterises this syndrome is massive haemorrhagic necrosis, the presence of other lesions related to blood vessels and bile ducts in five of the six cases described here suggests that there may be some overlap with other forms of graft damage. 
Two of our cases showed evidence of bile duct loss and foam cell arteriopathy - the lesions which characterise chronic rejection of the liver allograft and the vanishing bile duct syndrome (VBDS) ${ }^{728}{ }^{29}$ Furthermore, small areas of perivenular hepatocyte necrosis and congestion or haemorrhage are seen in acute cellular rejection, acute VBDS, and chronic rejection. ${ }^{38}$ In acute rejection these lesions are reversible and do not progress in most cases. In chronic rejection the lesions are gradually replaced by fibrous tissue. Membranous expression of HLA class I antigens has been observed in perivenular hepatocytes in rejecting liver allografts, ${ }^{30-34}$ and we have recently described a pan-acinar pattern of membranous class I antigen display in some cases of massive haemorrhagic necrosis. ${ }^{34}$ These observations suggest that there may be a common underlying mechanism for cases of massive haemorrhagic necrosis and other forms of graft damage with different components of the liver being affected to a greater or lesser degree in different cases. Recent studies have implicated humoral mechanisms as the cause of damage to bile ducts ${ }^{35}$ and vascular endothelium ${ }^{36}$ in cases of chronic rejection, and these findings would further support a unifying mechanism of humoral-mediated graft damage.

The clinical implication of veno-obliterative lesions in four of six cases described here is uncertain. In places the pattern of loose intimal fibrosis resembles the changes seen in acute veno-occlusive disease of the liver due to drugs and other toxic agents. ${ }^{37}$ Azathioprine has been described as a cause of hepatic venoocclusive disease following renal transplantation ${ }^{38} 39$ and was used in three of the four patients who developed veno-obliterative lesions. Elsewhere the picture more closely resembles a severe form of rejection endotheliitis. The difficulty in distinguishing between these two possible causes for veno-occlusive lesions was also seen in a case of acute VBDS described recently by Ludwig et al. ${ }^{8}$ Although a primary venoocclusive lesion possibly related to immunosuppressive treatment cannot be entirely ruled out, the absence of any hepatic vein lesion in two of our cases with otherwise typical haemorrhagic necrosis and the presence of fairly mild lesions in another two cases makes this unlikely to be the only mechanism involved. A more likely explanation is that venoocclusive lesions are a secondary event occurring as a result of perivenular ischaemic injury. Indeed, a similar mechanism has been proposed for the pathogenesis of toxic veno-occlusive disease in man and animals, ${ }^{4041}$ and secondary veno-occlusive lesions are increasingly recognised in a variety of chronic liver diseases including alcoholic hepatitis, primary biliary cirrhosis, and other forms of cirrhosis. ${ }^{42-44}$

Further studies are clearly required to elucidate the precise mechanisms underlying this severe complica- tion of liver transplantation. More than one aetiological factor may play a part and haemorrhagic graft necrosis may represent the end stage of several different insults to the liver. Nevertheless, the changes described in the six cases presented here seem sufficiently distinctive to regard this as a specific posttransplant syndrome. Until the aetiology is elucidated we suggest that the term "massive haemorrhagic necrosis" be used to described future cases. This term is descriptively accurate and avoids potentially misleading inferences concerning underlying mechanisms.

We thank Mr A A Cooper for assistance with photography. Miss A J Wright and Miss M Dee typed the manuscript.

\section{References}

1 Starzl TE, Putnam CW. Acute reflection and hepatic gangrene. In: Experience in hepatic transplantation. Philadelphia: W B Saunders Co, 1969:308-28.

2 Starzl TE, Iwatsuki S, VanThiel DH, et al. Evolution of liver transplantation Hepatology 1982;2:614-36.

3 Demetris AJ, Lasky S, VanThiel DH, et al. Pathology of Hepatic Transplantation: a review of 62 adult allograft recipients immunosuppressed with a cyclosporine/steroid regimen. $\mathrm{Am} \mathrm{J}$ Pathol 1985;118:151-61.

4 Hübscher SG, Clements D, Elias E, et al. Biopsy findings in cases of rejection of liver allograft. J Clin Pathol 1985;38:1366-73.

5 Hübscher SG. Loss of bile ducts after liver transplantation. Lancet 1987;ii:1149.

6 Hübscher SG. Histopathological findings in chronic rejection of the liver allograft. J Pathol 1988;353A.

7 Wight DGD. Pathology of rejection. In: Calne RY, ed Liver transplantation. London: Grune and Stratton, 1983:247-77.

8 Ludwig J, Wiesner RH, Batts P, et al. The acute vanishing bile duct syndrome (acute irreversible rejection) after orthotopic liver transplantation. Hepatology 1987;7:476-83.

9 Poulsen H, Christofferson P. Atlas of liver biopsies. Munksgaard: J B Lippincott Company, 1979:100-1.

10 Portmann B, O'Grady J, Williams R. Disease recurrence following orthotopic liver transplantation. Transplant Proc 1986;18 (Suppl 4):136-42.

11 Starzl TE, Groth CG, Brettschneider L, et al. Orthotopic homotransplantation of the human liver. Ann Surg 1968; 168:392-415.

12 Brettschneider L, Tong JL, Boose DS, et al. Specific bacteriologic problems with canine orthotopic liver transplantation. Arch Surg 1968;97:313-22.

13 Myerowitz RL. Diseases caused by herpes simplex virus. In: The pathology of opportunistic infections. New York: Raven Press, 1983;177-92.

14 Myerowitz RL. Cutaneous and disseminated Herpes zoster. In: The pathology of opportunistic infections. New York: Raven Press, 1983:193-8.

15 Myerowitz RL. Disseminated adenovirus infection. In: The pathology of opportunistic infections. New York: Raven Press, 1983:205-12.

16 Carmichael GP, Zahradnik JM, Moyer GH, et al. Adenovirus hepatitis in an immunosuppressed adult patient. Am $J$ Clin Pathol 1979;71:352-5.

17 Zahradnik JM, Spencer MJ, Porter DD. Adenovirus infection in the immunosuppressed patient. Am J Med 1980;68:725-32.

18 Philip AGS, Larson EJ. Overwhelming neonatal infection with echo 19 virus. J Pediatr 1973;82:391-7.

19 Hosier DM, Newton WA. Serious coxsackie infection of infants 
and children: Myocarditis, meningoencephalitis and hepatitis. Am J Dis Child 1958;96:251-67.

20 Starzl TE, Putnam CW. Reflection crisisoln. Experience in hepatic transplantation. Philadelphia: W B Saunders Co, 1969:283-94.

21 Snover DC, Sibley RK, Freese DK, et al. Orthotopic liver transplantation; a pathological study of 63 serial liver biopsies from 17 patients with special reference to the diagnostic features and natural history of rejection. Hepatology 1984;4:1212-22.

22 Williams JW, Peters TG, Vera SR, et al. Biopsy-directed immunosuppression following hepatic transplantation in man. Transplantation 1985;39:589-96.

23 Knechtle SJ, Kolbeck PC, Tsuchimoto S, et al. Hepatic transplantation into sensitized recipients. Demonstration of hyperacute rejection. Transplantation 1987;43:8-12.

24 Snover DC. The pathology of acute rejection. Transplant Proc 1986;18:123-7.

25 Gordon RD, Iwatsuki S, Esquivel CO, et al. Liver transplantation across ABO blood groups. Surgery 1986;100:342-8.

26 Mori W, Shiga J, Kato A. Extensive hepatic cell necrosis produced by the Schwartzman mechanism. Virchows Arch (Pathol Anat) 1979;382:179-89.

27 Mori W, Aoki N, Shiga J. Acute hepatic cell necrosis experimentally produced by viral agents in rabbits. Am J Pathol 1981;103:31-8.

28 Portmann B, Neuberger JM, Williams R. Intrahepatic bile duct lesions. In: Calne RY, ed. Liver transplantation. London: Grune and Stratton, 1983:279-87.

29 Grond J, Gouw ASH. Poppema S, Sloof MJH, Gips CH. Chronic rejection in liver transplants: a histopathologic analysis of failed grafts and antecedent serial biopsies. Transplant Proc 1986; 18:128-35.

30 Nagafuchi Y, Hobbs KEF, Thomas HC, Scheuer PJ. Expression of beta-2-microglobulin on hepatocytes after liver transplantation. Lancet 1985; i:551-4.

31 So SKS, Platt JL, Ascher NL, Snover DC. Increased expression of Class I major histocompatibility antigens on hepatocytes in rejecting human liver allografts. Transplantation 1987;43:79-85.

32 Gouw ASH, Houthoff HJ, Huitema S, Beelen JM, Gips CH, Poppema S. Expression of major histocompatibility complex antigens and replacement of donor cells by recipient ones in human liver grafts. Transplantation 1987;43:291-6.
33 Steinhoff G, Wonigeit K, Pichimayr R. Analysis of sequential changes in major histocompatibility complex expression in human liver grafts after transplantation. Transplantation 1988;45:394-401.

34 Hübscher SG, Adams DH, Elias E. Beta-2-microglobulin expression in the liver following liver transplantation. J Clin Pathol 1988;41:1049-57.

35 Donaldson PT, Alexander GJM, O'Grady J, et al. Evidence for an immune response to HLA class I antigens in the vanishing-bile duct syndrome after liver transplantation. Lancet 1987; i:945-8.

36 Demetris AJ, Markus BH, Burnham J, et al. Antibody deposition in liver allografts with chronic rejection. Transplant Proc 1987;19:121-25.

37 Bras G, Brandt KG. Vascular disorders. In: McSween RNM, Anthony PP, Scheuer PJ, eds. Pathology of the Liver. Edinburgh: Churchill Livingstone, 1987;478-502.

38 Marubbio AT, Danielson B. Hepatic veno-occlusive disease in a renal transplant patient receiving azathioprine. Gastroenterology 1975;69:739-43.

39 Weitz H, Gokel JM, Loeschke K, Possinger K, Eder M. Venoocclusive disease of the liver in patients receiving immunosuppressive therapy. Virchows Arch (Pathol Anat) 1982;395: 245-56.

40 Stirling GA, Bras G, Urquhart AE. The early lesions in venoocclusive disease of the liver. Arch Dis Child 1962;37:535-8.

41 Rappaport AM, Knoblauch M, Zeilin S, et al. Experimental hepatic veno-occlusive disease. Advances in Microcirculation 1969;2:69-79.

42 Goodman ZD, Ishak K. Occlusive venous lesions in alcoholic liver disease: a study of 200 cases. Gastroenterology 1982;83:786-96.

43 Nakanuma Y, Ohta G, Doishita K. Quantitation and serial section observations of focal veno-occlusive lesions of hepatic veins in liver cirrhosis. Virchows Arch (Pathol Anat) 1985;405:429-38.

44 Burt AD, MacSween RNM. Hepatic vein lesions in alcoholic liver disease: retrospective biopsy and necropsy study. J Clin Pathol 1986;39:63-7.

Requests for reprints to Dr S G Hübscher, Department of Pathology, The Medical School, University of Birmingham, Birmingham B15 2TJ, England. 